\title{
Empoderamento das mulheres beneficiárias do Programa Bolsa Família na percepção dos agentes dos Centros de Referência de Assistência Social
}

\author{
Nathalia Carvalho Moreira \\ Universidade Federal de Viçosa \\ Marco Aurélio Marques Ferreira \\ Universidade Federal de Viçosa \\ Afonso Augusto Teixeira de Freitas Carvalho Lima \\ Universidade Federal de Viçosa \\ Ivan Beck Ckagnazaroff \\ Universidade Federal de Minas Gerais
}

\begin{abstract}
Este trabalho teve como objetivo analisar o empoderamento das mulheres beneficiárias do Programa de Transferência de Renda, conhecido como "Programa Bolsa Família", na percepção dos agentes sociais dos Centros de Referência de Assistência Social (Cras). Para tanto, realizou-se um estudo de caso múltiplo, tendo como sujeitos de pesquisa 11 gestores de diferentes Cras do estado de Minas Gerais. A partir da técnica de análise de conteúdo, as respostas das perguntas, que compuseram as entrevistas, foram agrupadas de acordo com as categorias Bolsa Família, Cras e Mulher. Os resultados apontam a importância do Cras na execução do Programa Bolsa Família e no processo de empoderamento, pois a convivência e a participação neste local têm contribuído para a conscientização sobre direitos, para a inserção social e para a melhoria do bem-estar das mulheres, fatores evidenciados por intermédio do interesse das mulheres por cursos, oficinas, informações sobre programas sociais e atendimento psicológico. Na percepção dos agentes, foi possível observar melhoria nas condições de vida, nas relações familiares, conscientização e autoestima, implicando reflexos sobre o empoderamento feminino. Portanto, embora sendo um processo lento e embrionário, pode-se dizer que o ciclo do empoderamento das mulheres beneficiárias do Bolsa Família pode ser completado, pois consegue atingir as três dimensões (individual, familiar e comunitária).
\end{abstract}

Palavras-chave: políticas públicas; Programa Bolsa Família; empoderamento; Centros de Referência de Assistência Social.

Artigo recebido em ago. 2010 e aceito em maio 2011. Os autores agradecem à Fapemig pelo apoio concedido à pesquisa. 
The empowerment of the women who are beneficiary from the BolsaFamília Program' on the perception of the Social Assistance Reference Centers' agents

This study was carried out to analyze the empowerment of the women who are beneficiary from the Income Transference Program so-called "Programa Bolsa Família" under the social agents' perception in the Social Assistance Reference Centers (Cras). So, a multiple-case study involving eleven managers from different Cras of the Minas Gerais State was conducted. From the content analysis technique, the answers to the questions composing the interviews were grouped according to the categories: BolsaFamília, Cras and Woman. The results point out the importance of the Cras for either execution of the "Programa Bolsa Família" and the empowerment process, since the acquaintanceship and participation in this location have contributed to the awareness of the rights for the social insertion and the improvement of the women's welfare. Those factors are evidenced through the women's interest for courses, workshops, information on the social programs and psychological attendance. On the agents' perception, it was possible to observe the improvement in life conditions, family relationships, awareness and self-esteem, therefore involving reflexes on the women's empowerment. Although being a slow and embryonic process, it can be said that the empowerment cycle of the women benefiting from the Programa Bolsa Família can be completed, since it reaches the three dimensions: individual, familiar and communitarian.

Keywords:public policies; Programa Bolsa Família; empowerment; Social Assistance Reference Centers.

\section{Introdução}

Este trabalho teve como objetivo analisar o processo de empoderamento das mulheres beneficiárias do Programa de Transferência de Renda Mínima (Programa Bolsa Família — PBF) na percepção dos agentes sociais (psicólogos e assistentes sociais) envolvidos com os Centros de Referência de Assistência Social (Cras).

Em 2008, o Ministério do Desenvolvimento Social e Combate à Fome (MDS) propôs a expansão da Política Nacional de Assistência Social (PNAS), por meio do Programa de Atenção Integral à Família (Paif), visando à melhoria no acompanhamento das famílias. O Paif é implementado por intermédio dos Cras, localizados em territórios de vulnerabilidade social, que atuam com as famílias e indivíduos em seu contexto comunitário.

Essas unidades desenvolvem serviços socioassistenciais, socioeducativos e de convivência voltados para as famílias consideradas vulneráveis e prioritariamente para as famílias beneficiárias do PBF. Neste contexto, o PBF está inserido na PNAS, a qual estabelece que as ações do Cras devem ser focalizadas na família (Ministério do Desenvolvimento Social e Combate à Fome, 2004).

Nesse âmbito, compreender a percepção dos agentes do sistema público assim como sua importância no processo de empoderamento é fundamental na prática e execução de projetos de desenvolvimento social.

Gohn (2004) afirma que o empoderamento, entendido como a capacidade de os indivíduos e grupos poderem decidir sobre as questões que lhes dizem respeito, vem sendo utilizado 
no âmbito das políticas públicas, o que enfatiza seu protagonismo para geração de desenvolvimento autossustentável.

Segundo Romano (2002), a abordagem do empoderamento implica o desenvolvimento de capacidades das pessoas pobres e excluídas socialmente para superar as principais fontes de privação de liberdades. Neste sentido, torna-se relevante analisar o empoderamento das mulheres em situação de pobreza.

Neste trabalho, o empoderamento foi estudado por intermédio da análise da aplicação e da administração dos recursos recebidos, compreensão do PBF e condicionalidades e, especialmente, por meio do comportamento das mulheres, conforme a percepção dos sujeitos de pesquisa em relação aos maridos, filhos, trabalho, bem como seu conhecimento a respeito do Cras.

Conforme estudos disponíveis na literatura, o convívio no Cras reflete positivamente na vida das famílias (Ministério do Desenvolvimento Social e Combate à Fome, 2009). Assim, este trabalho justifica-se à medida que o Cras torna-se um espaço de convívio e interação social, que visa a potencialização da autonomia das famílias e não apenas a diminuição imediata das vulnerabilidades.

\section{Referencial teórico}

\subsection{Programas de transferência de renda e o Programa Bolsa Família}

Os primeiros programas de transferência condicionada de renda foram criados no México e no Brasil, em 1997. Por conseguinte, foram criados programas semelhantes em outros países da América Latina, transferindo, preferencialmente às mães, uma pequena soma de dinheiro sob a condição de cumprimento de algumas metas de saúde e educação, tais como levar os filhos ao posto de saúde e à escola (Villatoro, 2005).

O programa mexicano, inicialmente denominado Progresa e posteriormente Oportunidades, apresentou resultados satisfatórios que se tornaram exemplo, e organismos de financiamento, como o Banco Interamericano para o Desenvolvimento (BID), interessaram-se em financiar sua replicação (Coady e Parker, 2004).

Rubalcava e colaboradores (2009) analisaram as mulheres beneficiárias do Progresa e perceberam que essas mulheres são mais cuidadosas na administração dos benefícios, pois são mais pacientes do que os homens e pensam no futuro. Considerados em conjunto, os resultados sugerem que programas de transferência de renda convergem para uma mudança no equilíbrio de poder dentro das famílias.

A escolha das mães, segundo Medeiros e colaboradores (2007), reforça a legitimidade do papel feminino, havendo indicações de que as mulheres administram os recursos de modo mais favorável à família, por exercerem papéis sociais mais relacionados aos cuidados com os filhos e ao cotidiano da casa.

O programa da Nicarágua (Red de Protección Social), criado em 2000, ficou conhecido internacionalmente em virtude de seus efeitos positivos na saúde e educação das crianças, 
principalmente por utilizar as condicionalidades como um mecanismo para iniciar processos de mudanças comportamentais entre os beneficiários.

No entanto, conforme Moser (2009), o programa foi interrompido em 2006, devido à falta de apoio popular e político, pois os resultados positivos do programa foram ofuscados por uma "percepção errônea" de parte da população, que o considerava uma forma de ajudar a perpetuar a pobreza, ao simplesmente entregar dinheiro aos pobres.

Dessa forma, programas de transferência de renda também precisam de apoio popular, sendo necessário divulgar frequentemente para a população quais são seus objetivos e seus resultados (Moser, 2009).

Em 2003, no Brasil, o PBF unificou todos os benefícios sociais (Bolsa Escola, Bolsa Alimentação, Cartão Alimentação e Auxílio Gás) do governo federal em um único programa, o que reduziu burocracias, criou mais facilidade no controle dos recursos e trouxe mais transparência ao programa.

O PBF vem impulsionando o número de matrículas e diminuindo a taxa de abandono nas escolas, reduzindo a vulnerabilidade e permitindo às pessoas pobres reivindicar direitos sociais, além de refletir-se na diminuição das desigualdades de gênero, fatores estes que facilitam o desenvolvimento humano (Pnud, 2007-2008).

Conforme o Núcleo de Estudos e Pesquisa sobre a Mulher da Universidade de Brasília (Agende, 2006), o PBF tem obtido impactos relevantes na condição social das mulheres beneficiárias, especialmente na visibilidade enquanto consumidoras, na afirmação da autoridade no espaço doméstico e na mudança da percepção como cidadãs.

Neste contexto, o PBF pode ocasionar diminuição das desigualdades de gênero bem como efeitos no empoderamento e na autonomia feminina.

Segundo Bronzo (2008), o PBF traz efeitos no reordenamento do espaço doméstico, na autoestima, no empoderamento e acesso feminino ao espaço público (como participação em conselhos comunitários e escolares), possibilitando às mulheres maior poder de barganha, maior capacidade de fazer escolhas e maior poder de decisão sobre o uso do dinheiro.

Bronzo (2008) também afirma que existem questionamentos sobre o efeito contrário das transferências de renda, que poderiam perpetuar papéis de submissão de gênero à medida que a provisão de renda às famílias faria com que as mães se retirassem do mercado de trabalho e se dedicassem, exclusivamente, aos cuidados dos filhos.

Dessa forma, é importante analisar a percepção dos agentes sociais quanto ao impacto do PBF sobre o empoderamento feminino, uma vez que tais transferências concedem à mulher a responsabilidade de garantir a melhor aplicação dos recursos e o controle no atendimento às condicionalidades exigidas para a manutenção do benefício.

\subsection{O sistema de proteção social brasileiro e o Cras}

A Constituição Federal de 1988 significou um avanço na área da proteção social ao instituir a seguridade social — composta pelas políticas de saúde, previdência social e assistência social (Silvaet al., 2007). 
No Brasil, a Lei Orgânica de Assistência Social foi aprovada em 1993. No entanto, somente a partir de 2004 a Política Nacional de Assistência Social (Pnas) foi consolidada, expressando os pilares do sistema de proteção social brasileiro.

Segundo a Pnas, a prioridade da proteção social é a família, fortalecendo seus vínculos, promovendo autonomia e ofertando serviços locais de socialização.

O Sistema Único de Assistência Social (Suas), implantado a partir de 2005, efetiva - na prática - a assistência social como política pública de Estado, alterando o modelo de gestão e a forma de financiamento da assistência social, estabelecendo um novo pacto federativo entre União, estados, Distrito Federal e municípios, que garante autonomia legal em regime de mútua colaboração institucional (Russo, 2010).

A Proteção Social Básica (PSB) do Suas é destinada à população que vive em situação de vulnerabilidade decorrente da pobreza, privação e/ou fragilização de vínculos afetivos, discriminações etárias, étnicas, de gênero ou por deficiências.

Dessa maneira, o que configura a PSB nos municípios e no Distrito Federal é a existência dos Cras, um dos equipamentos da rede de proteção básica que marca a presença do Suas nos municípios. O Cras é a unidade pública estatal responsável pela oferta de serviços continuados de assistência social, promovendo serviços e projetos locais de acolhimento, de convivência e de socialização para famílias e indivíduos.

Em 2008, o Ministério do Desenvolvimento Social e Combate à Fome assinou, com o governo de Minas Gerais, um termo de cooperação técnica e financeira ampliando os investimentos para consolidar o Suas (Ministério do Desenvolvimento Social e Combate à Fome, 2006b). Assim, a descentralização é tendência contínua e vem sendo favorecida nos processos de reforma do Estado como principal força de reordenamento e dinamização das novas políticas, devido à credibilidade e legitimidade dos sucessos já alcançados (Draibe, 1997).

No modelo de gestão descentralizada do PBF, os gestores municipais dos Cras são os principais agentes públicos junto às famílias, pois, como executores locais, podem identificar mudanças nas famílias e realizar as devidas intervenções na administração de benefícios.

\subsection{Empoderamento}

Ao considerar o duplo caráter da pobreza - como fenômeno que envolve dimensões objetivas de falta de recursos e também dimensões subjetivas relativas a valores e comportamentos —, é necessário alterar as condições limitadoras, investir no empoderamento, na autonomia, nas competências e na capacidade de autodesenvolvimento, visando à ampliação da capacidade de ação das pessoas para a superação da pobreza (Bronzo, 2008).

A Organização Mundial de Saúde (1998) define empoderamento como:

um processo social, cultural, psicológico ou político através do qual indivíduos e grupos sociais tornam-se capazes de expressar suas necessidades, explicitar suas preocupações, perceber estratégias de envolvimento na tomada de decisões e atuar política, social e culturalmente para satisfazer suas necessidades. 
Segundo Sen (1997), empoderar a sociedade é equilibrar as relações de poder em favor dos que têm menos recursos, de modo que o empoderamento tem relação direta com equidade.

De acordo com Mageste e colaboradores (2008), o empoderamento possui três níveis: o individual, o relacional e o contextual, como uma espiral que vai se ampliando e é interligada e circundada por relações de poder. Dessa forma, estão intimamente ligados, interferindo e exercendo pressões mútuas.

Portanto, modificações em um dos níveis acabam gerando mudanças e adaptações nos demais e a ação de um acaba gerando reação de outro. A transformação na estrutura de poder que mantém esta estrutura é lenta e gradual, embora o processo de empoderamento possa se iniciar em qualquer dessas instâncias, só se completando quando consegue permear todas (Mageste et al., 2008).

Segundo Gohn (2004), o empoderamento individual tem como indicadores a autoestima, autoconfiança e autoafirmação, tendo como foco a melhoria nas condições de vida.

Moore (2009) utiliza a concepção de portfolio de ativos, que incorpora aspectos do papel das relações familiares como elementos de empoderamento. O autor procurou entender como, em situações de crise, as famílias se comportam. Para isto, mapeou a capacidade dos pobres em usar seus recursos para enfrentar e reduzir sua vulnerabilidade.

O empoderamento comunitário, por outro lado, não possui indicadores universais, podendo envolver empoderamento pessoal, desenvolvimento de pequenos grupos de apoio mútuo, organizações comunitárias, associações e ação social e política, focalizando a conquista e defesa de direitos, a influência na ação do Estado, com capacidade de demanda e interferência direta ou indireta da população nas decisões políticas.

Sinteticamente, pode-se compreender o empoderamento de acordo com a síntese apresentada no quadro 1 .

Quadro 1

Níveis e focos de empoderamento

\begin{tabular}{|ll|}
\hline Níveis de empoderamento & \multicolumn{1}{c|}{ Focos } \\
\hline Individual & Melhoria na condição de vida, conscientização, autoestima e autoconfiança \\
Relacional ou Familiar & Inclusão social, educação, qualificação, capacitação e melhoria das relações familiares \\
Contextual ou Comunitário & $\begin{array}{l}\text { Conquista e defesa de direitos, formação de grupos de apoio, organizações comunitárias, } \\
\text { associações e ação social }\end{array}$ \\
\hline
\end{tabular}

Fonte: Elaborado pelos autores, a partir de Gohn (2004), Bronzo (2008) e Mageste e colaboradores (2008).

Conforme Uphoff (1993) e Gohn (2004), as ações mais bem-sucedidas em prol do empoderamento são aquelas que, além de auxiliar os grupos excluídos a assegurar sua sobrevivência, ultrapassam a assistência social e buscam a mobilização junto a movimentos e redes mais amplas, com o objetivo de empoderá-los, procurando influenciar o processo político. 
Devido à dificuldade de se mensurar o empoderamento, o Fórum Econômico Mundial (2005) definiu cinco dimensões para o empoderamento e oportunidade das mulheres: participação econômica, oportunidade econômica, empoderamento político, conquistas educacionais e saúde e bem-estar.

Em relação ao empoderamento das mulheres, Costa (2000) afirma que este representa um desafio às relações patriarcais, em especial ao poder dominante dentro da família, que quase sempre é masculino.

Dessa maneira, o empoderamento das mulheres significa uma mudança na dominação tradicional de homens sobre mulheres, garantindo-lhes autonomia no que se refere ao controle de seus corpos, à sexualidade, ao direito de ir e vir, bem como um sentimento de repulsa à violência e às decisões unilaterais masculinas que afetam toda a família (Costa, 2000).

Segundo Sen (2001), oferecer às mulheres educação e emprego (de maneira a fortalecer sua autonomia) seria o primeiro passo para aumentar seu poder de voz dentro e fora da família e permitir sua inclusão em um debate que as excluía. Contudo, conforme Fialho (2007), o PBF também pode trazer efeitos favoráveis nas relações de poder das mulheres, pois estudos confirmam que o benefício colocou a mulher em situação de vantagem em relação aos outros membros familiares, com um poder simbólico, pois a família passa a respeitá-la mais.

\section{Metodologia}

Este estudo classifica-se como qualitativo e, quanto aos fins, trata-se de uma pesquisa descritiva e exploratória, pois buscou obter mais familiaridade sobre o assunto e registrar, classificar e interpretar os fatos (Gil, 2006).

Realizou-se um estudo de caso múltiplo, tendo como sujeitos de pesquisa 11 gestores de Cras, incluindo os ocupantes de cargos de psicólogos e assistentes sociais, os quais foram identificados de E1 a E11. A etapa de coleta de dados se deu por intermédio de 11 entrevistas individuais (Apêndice A). As entrevistas foram gravadas e, em seguida, as respostas foram transcritas, classificadas e agrupadas de acordo com as categorias que se objetivou analisar, por intermédio da análise de conteúdo.

A entrevista é a técnica mais utilizada na abordagem qualitativa. Segundo Yin (2001), é uma das mais importantes fontes de informações para um estudo de caso, tendo como vantagens a flexibilidade, a rapidez e a quantidade de dados que podem ser obtidos.

\subsection{Procedimentos de análise de dados}

\subsubsection{Análise de conteúdo}

Conforme Bardin (2009), a análise de conteúdo é uma técnica de investigação por intermédio de uma descrição objetiva, sistemática e quantitativa do conteúdo manifesto das comunica- 
ções, e cuja finalidade é a interpretação, pois fundamental não é aquilo que a mensagem diz à primeira vista, mas o que ela veicula em seu contexto.

Dessa maneira, foi realizada a categorização que, segundo Leopardi e Rodrigues (1999), é uma operação que classifica elementos constitutivos de um conjunto, por diferenciação e por reagrupamento, consideradas suas características particulares.

Assim, após a transcrição das entrevistas, as categorias foram elaboradas, advindas da análise quantitativa das respostas para identificação da frequência sobre o tema.

Franco (2005) afirma que a unidade de registro (palavra) é a menor parte do conteúdo. Entretanto, optou-se pela análise do tema por ser o que melhor atendia à questão investigativa.

As categorias, subcategorias e temas de análise deste estudo são apresentados no quadro 2.

Quadro 2

Categorias, subcategorias e temas de análise

\begin{tabular}{|c|c|c|}
\hline Categorias & Subcategorias & Temas de Análise \\
\hline & & Autonomia \\
\hline & & Renda \\
\hline & Significado & Direito do governo \\
\hline & & Autoestima \\
\hline & & Não compreendem \\
\hline & & Alimentação \\
\hline & & Roupas \\
\hline & Aplicação & Material escolar \\
\hline & dos & Cesta básica \\
\hline \multirow[t]{10}{*}{ Bolsa Família } & recursos & Filhos \\
\hline & & Celular \\
\hline & & Bebida alcoólica \\
\hline & & Punição \\
\hline & & Responsabilidade de mãe \\
\hline & & Fardo \\
\hline & Condicionalidades & Preocupação em realizar \\
\hline & & Falta de compromisso \\
\hline & & Não compreendem \\
\hline & & Cumprem corretamente \\
\hline
\end{tabular}




\begin{tabular}{|c|c|c|}
\hline Categorias & Subcategorias & Temas de Análise \\
\hline \multirow{2}{*}{ Cras } & $\begin{array}{l}\text { Motivo } \\
\text { de } \\
\text { procura }\end{array}$ & $\begin{array}{l}\text { Auxílio alimentação } \\
\text { ProJovem } \\
\text { Benefício } \\
\text { Bolsa Família } \\
\text { Problemas de família } \\
\text { Cursos }\end{array}$ \\
\hline & $\begin{array}{c}\text { Mudança } \\
\text { de } \\
\text { comportamento }\end{array}$ & $\begin{array}{l}\text { Compreensão dos direitos } \\
\text { Compreensão do Cras } \\
\text { Inserção social } \\
\text { Bem-estar } \\
\text { Atividades sociais } \\
\text { Atividades educativas }\end{array}$ \\
\hline \multirow[b]{2}{*}{ Mulher } & Família & $\begin{array}{l}\text { Conscientização dos direitos } \\
\text { Não submissão aos maridos } \\
\text { Assistência jurídica } \\
\text { Separação } \\
\text { Menos violência doméstica }\end{array}$ \\
\hline & Trabalho & $\begin{array}{l}\text { Não trabalham } \\
\text { Medo de perder o benefício } \\
\text { Não procuram emprego } \\
\text { Bicos } \\
\text { Oficinas de geração de trabalho e renda } \\
\text { Trabalho sazonal } \\
\text { Acomodação }\end{array}$ \\
\hline
\end{tabular}

Fonte: Elaborado pelos autores.

\section{Resultados}

\subsection{Caracterização dos municípios}

As seguintes regiões foram representadas no estudo: Sul, Zona da Mata e Metropolitana de Belo Horizonte, localizadas no estado de Minas Gerais. 
A seleção dos municípios foi realizada de acordo com o Índice de Gestão Descentralizada (IGD) e a acessibilidade. O IGD é um índice de eficiência da gestão que combina a integridade, a qualidade e a atualização das informações sobre os cumprimentos das condicionalidades da área de educação e de saúde (Bolsa Família Informa, 2008).

Procurou-se concentrar a realização do estudo em municípios que possuíssem IGD intermediário (tabela), pois, segundo Monteiro (2008), 68,9\% dos municípios de Minas Gerais encontram-se com a média 0,74, que está contida entre os escores de fraco e bom.

Tabela

Caracterização dos municípios

\begin{tabular}{|c|c|c|c|c|c|}
\hline Municípios & Região & $\begin{array}{l}\text { Habitantes }^{1} \\
\text { (mil) }\end{array}$ & $\begin{array}{l}\text { Beneficiários } \\
\text { Bolsa Família² }\end{array}$ & $\mathrm{IGD}^{2}$ & $\begin{array}{c}\text { Quantidade } \\
\text { de Cras }\end{array}$ \\
\hline Três Pontas & \multirow{4}{*}{ Sul } & 54.149 & 2.707 & 0,72 & 2 \\
\hline Santana da Vargem & & 7.222 & 660 & 0,86 & $1^{*}$ \\
\hline Varginha & & 121.785 & 1.549 & 0,64 & 4 \\
\hline Três Corações & & 75.776 & 4.051 & 0,71 & 2 \\
\hline Muriaé & \multirow{2}{*}{ Zona da Mata } & 99.628 & 5.533 & 0,82 & 2 \\
\hline Viçosa & & 74.171 & 3.469 & 0,76 & 1 \\
\hline Ribeirão das Neves & \multirow{4}{*}{ Metropolitana } & 349.307 & 16.587 & 0,69 & 8 \\
\hline Betim & & 441.748 & 17.024 & 0,68 & 8 \\
\hline Contagem & & 625.393 & 21.319 & 0,70 & 7 \\
\hline Esmeraldas & & 59.408 & 4.664 & 0,77 & 1 \\
\hline \multicolumn{2}{|l|}{ Média } & 190.859 & 7.756 & 0,735 & 3,88 \\
\hline
\end{tabular}

1 IBGE (2009); ${ }^{2}$ Ministério do Desenvolvimento Social e Combate à Fome (2010); * em processo de implementação.

Fonte: dados da pesquisa.

\subsection{A categoria Bolsa Família}

Nesta seção, pode-se visualizar a categoria Bolsa Família, suas subcategorias (Significado, Aplicação dos recursos e Condicionalidades) e temas de análise.

Os temas de análise foram assinalados nas colunas, de acordo com a citação dos sujeitos de pesquisa (quadro 3), tendo sido apuradas a quantidade total de observações e a frequência.

Como exemplo de interpretação, nota-se que o tema renda, da subcategoria Significado foi assinalado pelos entrevistados E2 a E11, totalizando 10 observações e frequência de $90,9 \%$. Nesse sentido, as tabelas referentes às demais categorias foram analisadas da mesma forma. 
Quadro 3

Análise de conteúdo da categoria Bolsa Família

\begin{tabular}{|c|c|c|c|c|c|c|c|c|c|c|c|c|c|c|c|}
\hline \multirow[b]{2}{*}{ Categoria } & \multirow[b]{2}{*}{ Subcategorias } & \multirow[b]{2}{*}{ Temas de análise } & \multicolumn{13}{|c|}{ Entrevistados } \\
\hline & & & 1 & 2 & 3 & 4 & 5 & 6 & 7 & 8 & 9 & 10 & 11 & $\mathrm{~T}^{1}$ & $\begin{array}{l}\mathrm{Ft}^{2} \\
\%\end{array}$ \\
\hline \multirow{19}{*}{ 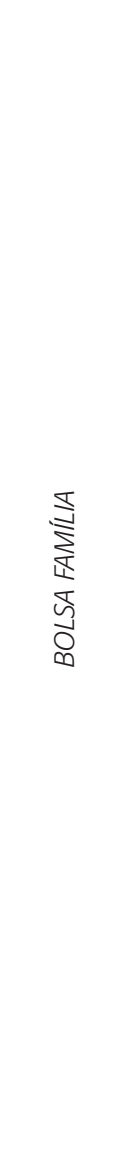 } & \multirow{5}{*}{ Significado } & Autonomia & $x$ & & $x$ & & & $x$ & & & & $x$ & & 4 & 36,3 \\
\hline & & Renda & & $x$ & $x$ & $x$ & $x$ & $x$ & $x$ & $x$ & $x$ & $x$ & $x$ & 10 & 90,9 \\
\hline & & Direito do governo & & & $x$ & $x$ & & & $x$ & $x$ & $x$ & & & 5 & 45,4 \\
\hline & & Autoestima & & & & & & $x$ & & & $x$ & & & 2 & 18,1 \\
\hline & & Não compreendem & & & & $x$ & $x$ & & $x$ & $x$ & $x$ & & & 5 & 45,4 \\
\hline & \multirow{7}{*}{$\begin{array}{l}\text { Aplicação dos } \\
\text { recursos }\end{array}$} & Alimentação & $x$ & $x$ & $x$ & $x$ & & $x$ & & $x$ & $x$ & $x$ & $x$ & 9 & 81,8 \\
\hline & & Roupas & $x$ & $x$ & $x$ & $x$ & $x$ & $x$ & & $x$ & $x$ & $x$ & $x$ & 10 & 90,9 \\
\hline & & Material escolar & $x$ & $x$ & $x$ & $x$ & $x$ & & $x$ & $x$ & $x$ & $x$ & $x$ & 10 & 90,9 \\
\hline & & Cesta básica & & & $x$ & & & & & $x$ & & & & 2 & 18,1 \\
\hline & & Filhos & & & $x$ & $x$ & $x$ & $x$ & & & $x$ & & & 5 & 45,4 \\
\hline & & Celular & & & & $x$ & & & & & $x$ & & & 2 & 18,1 \\
\hline & & Bebida alcoólica & & & & & $x$ & & $x$ & & & & & 2 & 18,1 \\
\hline & \multirow{7}{*}{ 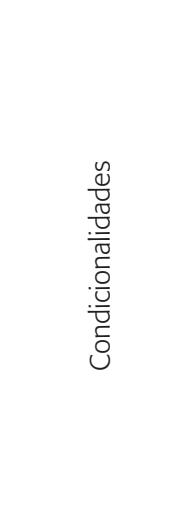 } & Punição & $x$ & & & & & & $x$ & & & & & 2 & 18,1 \\
\hline & & $\begin{array}{l}\text { Responsabilidade } \\
\text { de mãe }\end{array}$ & $x$ & & & & & & $x$ & & $x$ & & & 3 & 27,2 \\
\hline & & Fardo & $x$ & & & & & $x$ & & & & & & 2 & 18,1 \\
\hline & & $\begin{array}{l}\text { Preocupação em } \\
\text { realizar }\end{array}$ & & & $x$ & $x$ & & & & & & & & 2 & 18,1 \\
\hline & & $\begin{array}{l}\text { Falta de } \\
\text { compromisso }\end{array}$ & & $x$ & & & $\mathrm{x}$ & & $x$ & & $x$ & & $x$ & 5 & 45,4 \\
\hline & & Não compreendem & & $x$ & $x$ & $x$ & & & $x$ & $x$ & & & & 5 & 45,4 \\
\hline & & $\begin{array}{l}\text { Cumprem } \\
\text { corretamente }\end{array}$ & & & & & $x$ & $x$ & $x$ & & & $x$ & & 4 & 36,3 \\
\hline
\end{tabular}

${ }^{1} \mathrm{~T}=$ total de observações; ${ }^{2} \mathrm{FT}=$ frequência total.

Fonte: resultados da pesquisa.

Na subcategoria Significado, 45,4\% dos entrevistados afirmam que as beneficiárias não compreendem corretamente o significado do PBF, o que demonstra a necessidade de divulgação, conforme ressalta Moser (2009) em seu estudo.

O fator mais significativo de significado do PBF foi o tema Renda, com 90,9\% de frequência nas referências, conforme comenta E11: "São pessoas que têm muitos filhos, casaram muito cedo, não têm escolaridade, ou têm escolaridade muito baixa, e às vezes o BF é mesmo a única renda que esta família tem". 
Conforme Suaréz e colaboradores (2006), programas de transferência de renda têm impacto significativo sobre a sobrevivência, sendo importantes para a manutenção da vida, pois enfatizam o atendimento das exigências básicas do sistema de proteção aos direitos humanos.

Segundo Suplicy (2002), o pagamento em dinheiro confere às pessoas mais liberdade e economia de tempo, além de proporcionar maior eficiência para a aplicação dos recursos.

Neste sentido, 45,5\% dos entrevistados consideram que as mulheres compreendem o benefício como um direito a ser recebido do governo, porém a autonomia e a autoestima também são lembradas em percentagem menor (36,3\% e 18,1\%, respectivamente), sendo este outro aspecto observado, como afirma E3: "Elas se sentem importantes. Sempre que elas vêm fazer o cadastro no Cras, tem um espaço para colocar o documento. Elas tiram com certo orgulho o cartão da bolsa. Elas apresentam o cartão como se fosse um cartão de crédito".

Este depoimento reforça o empoderamento individual que, segundo Gohn (2004), tem como indicadores a autoestima, a autoconfiança e a autoafirmação, tendo como foco a melhoria na qualidade de vida da pessoa.

Neste quesito, emerge o tema "bancarização", pois, em sua maioria, essas mulheres nunca possuíram conta bancária ou sequer frequentaram agências bancárias, sendo este um fator que as ajudaria a serem legitimadas como cidadãs.

De acordo com Ananias e Coelho (2009), a conta bancária simplificada, mais do que uma facilidade para o recebimento do benefício, é um direito que está sendo estendido a quem nunca tinha tido essa oportunidade anteriormente.

Na subcategoria Aplicação dos Recursos surgiu a percepção de que as mulheres assistidas, em sua maioria, conseguem aplicar adequadamente os benefícios recebidos com alimentação, materiais escolares e roupas, destinando esta renda prioritariamente para os filhos.

Isto confirma a visão de empoderamento de Romano (2002), pois as mulheres desenvolvem capacidades para superar as principais fontes de privação ao destinar os recursos às necessidades mais proeminentes.

Em relação à destinação dos recursos do PBF, os entrevistados ressaltam que grande parte do valor repassado às famílias é utilizada na compra de alimentos. Ressaltam também que, na maioria das vezes, as famílias compram apenas itens básicos, conforme afirma E2: "O principal é alimentação e o resto elas compram coisas não essenciais, biscoito, material escolar melhor... Roupas para os filhos... Mas a maioria gasta com alimentos básicos, fundamentais".

Villatoro (2005) aponta que o PBF contribui positivamente para a acumulação de capital humano e para maior frequência escolar. Nesse sentido, 90,9\% dos entrevistados confirmam a utilização do benefício para compra de materiais escolares.

Comparando esta realidade com os resultados do programa de transferência de renda da Nicarágua (Red de Protección Social), Gitter e Barham (2008) afirmam que o aumento das despesas com materiais escolares evidencia a preocupação das mães com a educação dos filhos.

Todavia, em menor escala, 18,1\% apontam a utilização irregular, com a compra de itens que podem ser considerados supérfluos, como o crédito para telefone celular e até mesmo bebidas alcoólicas; conforme afirma E4: "Algumas aplicam este dinheiro irregular. Compram coisas pra elas. Eu to atualizando os cadastros e eu pergunto em que está sendo gasto. Algumas eu até vejo que compra crédito de celular". 
É importante destacar que o uso inadequado dos benefícios pode causar o desligamento de uma família do PBF, fato este que ocorre somente após o quinto descumprimento de alguma condicionalidade, desde que fique comprovado.

A respeito da subcategoria Condicionalidades, as proposições veiculadas pelo PBF tratam de vincular as mulheres ao exercício da maternidade através do cumprimento de um conjunto de práticas, tais como ser fiscal da educação das crianças e administrar a renda familiar. A partir dessa vinculação, o PBF objetiva contribuir para a redução da evasão escolar e a repetência, bem como favorecer a melhoria da saúde, aumentar a autoestima das famílias e promover a valorização da mulher (Klein, 2007).

Conforme Ananias e Coelho (2009), as condicionalidades reforçam o caráter emancipador do PBF, e remetem ao Estado o dever de garantir o acesso aos direitos de educação e saúde. Essa mesma dimensão orienta a articulação do PBF com outros programas, como o Programa de Erradicação do Trabalho Infantil (Peti) e ProJovem.

Vale destacar que há também uma avaliação menos positiva a respeito das condicionalidades por parte das beneficiárias, uma vez que muitas mulheres questionam a obrigatoriedade do seu cumprimento (Monnerat et al., 2008).

De acordo com as autoras, a exigência de condicionalidades desperta bastante polêmica. Afirmam que a controvérsia aparece, por um lado, no reconhecimento de que as condicionalidades têm o objetivo de pressionar a demanda sobre os serviços de educação e saúde e, por outro lado, traduz-se na ideia de que à medida que o direito social é condicionado ao cumprimento de condicionalidades, os princípios de cidadania podem ser ameaçados (Monnerat et al., 2008).

Apesar dessa ponderação negativa, 36,3\% dos entrevistados afirmam que as mulheres cumprem corretamente as condicionalidades, enquanto $18,1 \%$ ressaltam que elas preocupamse em realizá-las. Contudo, em alguns casos, o cumprimento das condicionalidades é compreendido como uma obrigação ou uma penalidade para a maioria das mães. Assim, conforme E1... "Elas veem como uma punição. Como uma obrigação, como um fardo".

Embora 27,2\% dos agentes ressaltam que as mulheres compreendem as condicionalidades como uma responsabilidade inerente ao papel de mãe, sendo um exercício da maternagem, de acordo com Klein (2007), muitas ainda não desenvolveram esta responsabilidade, pois não cumprem as exigências (45,4\% afirmam que elas não compreendem e 45,4\% citam que há falta de compromisso). Nas palavras de E8: "Muitas não cumprem as condicionalidades, não sabem nem o que é. Muitas mães, muitas famílias, não cumprem".

Em referência a este aspecto, Rawlings e Rubio (2005) afirmam que há uma clara evidência do sucesso da primeira geração dos programas de transferência de renda na Colômbia, México e Nicarágua, em razão da compreensão das condicionalidades. Entretanto, retoma-se o pensamento de Moser (2009), que ressalta a necessidade de maior informação e conscientização para que as mães possam, realmente, cumprir o que lhes é exigido.

Portanto, apesar de algumas mães ainda não concordarem com a exigência das condicionalidades do PBF, é importante enfatizar sua realização, pois já são confirmados os efeitos sobre a saúde e a escolarização dos filhos. 


\subsection{A categoria Cras}

A categoria Cras possui duas subcategorias, que são Motivo de procura e Mudança de comportamento, seguidas dos temas de análise, conforme apresentado no quadro 4.

\section{Quadro 4}

\section{Análise de conteúdo da categoria Cras}

\begin{tabular}{|c|c|c|c|c|c|c|c|c|c|c|c|c|c|c|c|}
\hline \multirow[b]{2}{*}{ Categoria } & \multirow[b]{2}{*}{ Subcategorias } & \multirow[b]{2}{*}{ Temas de análise } & \multicolumn{13}{|c|}{ Entrevistados } \\
\hline & & & 1 & 2 & 3 & 4 & 5 & 6 & 7 & 8 & 9 & 10 & 11 & $\mathrm{~T}^{1}$ & $\begin{array}{c}\mathrm{FT}^{2} \\
\%\end{array}$ \\
\hline \multirow{12}{*}{$\hat{\Xi}$} & \multirow{6}{*}{$\begin{array}{c}\text { Motivo } \\
\text { de } \\
\text { procura }\end{array}$} & Auxílio alimentação & $x$ & $x$ & $x$ & $x$ & $x$ & $x$ & $x$ & $x$ & & $x$ & $x$ & 10 & 90,9 \\
\hline & & ProJovem & $x$ & & & & $x$ & $x$ & & & $x$ & & & 4 & 36,3 \\
\hline & & Benefício & $x$ & $x$ & & & & & & & & $x$ & & 3 & 27,2 \\
\hline & & Bolsa Família & & $x$ & & $x$ & $x$ & $x$ & & $x$ & $x$ & $x$ & $X$ & 8 & 72,7 \\
\hline & & Problemas de família & & $x$ & $x$ & & & $x$ & $x$ & & & & $X$ & 5 & 45,4 \\
\hline & & Cursos & & & $x$ & $x$ & $x$ & $x$ & & & $x$ & & & 5 & 45,4 \\
\hline & \multirow{6}{*}{$\begin{array}{c}\text { Mudança } \\
\text { de } \\
\text { comportamento }\end{array}$} & Compreensão dos direitos & $x$ & $x$ & & $x$ & & & $x$ & $x$ & & & $x$ & 6 & 54,5 \\
\hline & & Compreensão do Cras & $x$ & $x$ & & & & $x$ & & & & & & 3 & 27,2 \\
\hline & & Inserção social & & $x$ & & & $x$ & $x$ & & & & $x$ & $x$ & 5 & 45,4 \\
\hline & & Bem-estar & & $x$ & & $x$ & $x$ & $x$ & & $x$ & $x$ & & & 6 & 54,5 \\
\hline & & Atividades sociais & & $x$ & & & $x$ & & & & & & & 2 & 18,1 \\
\hline & & Atividades educativas & & $x$ & & $x$ & & $x$ & & $x$ & & & & 4 & 36,3 \\
\hline
\end{tabular}

$1 \mathrm{~T}=$ total de observações; ${ }^{2} \mathrm{FT}=$ frequência total.

Fonte: resultados da pesquisa.

Na subcategoria Motivo de procura, o Cras, também conhecido popularmente como Casa da Família, na percepção dos agentes tem sido procurado basicamente para resolver problemas emergenciais, como auxílio à alimentação (36,3\%), cesta básica $(54,5 \%)$, informações a respeito de programas sociais, como Bolsa Família (72,7\%) e ProJovem (36,3\%), além das oficinas, cursos de qualificação e geração de renda $(45,4 \%)$, que constituem grandes atrativos, como afirmam E5 e E1: "Desde cesta básica, às vezes vale transporte. Basicamente é isto. Mas a referência é o Bolsa Família. Tem os projetos, tem o ProJovem, cursos" (E5). "Buscando algum benefício, ajuda para alimentação, cesta básica. Eles pensam que a Casa da Família serve a cesta básica. Eles também procuram pelo ProJovem e BPC (Benefício de Prestação Continuada), sempre algum benefício" (E1).

Neste sentido, retomando o pensamento de Mageste e colaboradores(2008), o contato com o Cras pode influenciar o empoderamento relacional ou familiar, que tem como focos a inclusão social, a educação, a qualificação e a capacitação, porque (além da demanda por auxílio alimentação), conforme constatado, as mulheres procuram o Cras para obter informações e para realizar cursos e oficinas. 
Entre os entrevistados, 54,4\% afirmam que houve melhoria quanto ao bem-estar das mulheres e à compreensão de seus direitos; $27,2 \%$ afirmam que as mulheres compreenderam melhor a função do Cras; e 36,3\% relatam um aumento na participação em atividades educativas.

Neste panorama, evidencia-se a importância do Cras para o empoderamento comunitário que, conforme Gohn (2004), é focado no trabalho, conquista e defesa de direitos e participação de grupos. Conforme E1 e E2, o comportamento das mulheres mudou em relação a esses temas: "Eu vejo uma melhora muito grande, melhorou muito, tem famílias que antes não sabiam conversar nada. Você falava e elas ficavam de cabeça baixa, a partir do momento que a gente começou a atender, mudou completamente. A gente faz todo um trabalho de informações, de orientações" (E2). "Tem sido compreendido bem melhor o papel do Cras. Elas passam a compreender melhor os direitos. Estão começando a não confundir a função do Cras, a entender que tem assistência social, psicológica, cursos, oficinas" (E1).

Dessa forma, o acréscimo de informações pode ocasionar o empoderamento comunitário das mulheres, pois o conhecimento e o convívio no Cras podem aumentar sua capacidade de ação e de autodesenvolvimento, elementos necessários à superação da pobreza e promoção do empoderamento, conforme afirma Bronzo (2008).

\subsection{A categoria Mulher}

O quadro 5 expõe a categoria Mulher, suas subcategorias Família e Trabalho, seguidas dos temas de análise.

Quadro 5

Análise de conteúdo da categoria Mulher

\begin{tabular}{|c|c|c|c|c|c|c|c|c|c|c|c|c|c|c|c|}
\hline \multirow[b]{2}{*}{ Categoria } & \multirow[b]{2}{*}{ Subcategorias } & \multirow[b]{2}{*}{ Temas de análise } & \multicolumn{13}{|c|}{ Entrevistados } \\
\hline & & & 1 & 2 & 3 & 4 & 5 & 6 & 7 & 8 & 9 & 10 & 11 & $\mathrm{~T} 1$ & $\begin{array}{c}\mathrm{FT}^{2} \\
\%\end{array}$ \\
\hline \multirow{12}{*}{ 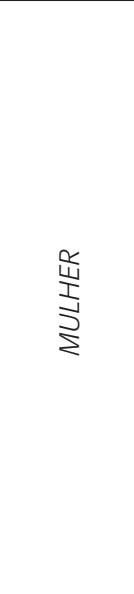 } & \multirow{5}{*}{ Família } & Conscientização dos direitos & $x$ & $x$ & $x$ & & & $x$ & & & $x$ & & & 5 & 45,4 \\
\hline & & Não submissão aos maridos & & $x$ & & $x$ & & & & & & & & 2 & 18,1 \\
\hline & & Assistência jurídica & & & $x$ & $x$ & & & & & $x$ & & & 3 & 27,2 \\
\hline & & Separação & & & $x$ & $x$ & & & & & $x$ & $x$ & & 4 & 36,3 \\
\hline & & Menos violência doméstica & & & & $x$ & & $x$ & & & & $x$ & & 3 & 27,2 \\
\hline & \multirow{7}{*}{ Trabalho } & Não trabalham & $x$ & $x$ & & & $x$ & $x$ & & & & & $x$ & 5 & 45,4 \\
\hline & & Medo de perder o benefício & $x$ & & & & & & $x$ & $\mathrm{x}$ & $x$ & $x$ & & 5 & 45,4 \\
\hline & & Não procuram emprego & $x$ & $x$ & $x$ & & $x$ & & & & & & & 4 & 36,3 \\
\hline & & Bicos & & & $x$ & $x$ & & & & & & $x$ & $x$ & 4 & 36,3 \\
\hline & & Oficinas de geração de trabalho e renda & & & $x$ & & & $x$ & & & & & & 2 & 18,1 \\
\hline & & Trabalho sazonal & & & & $x$ & & $x$ & & & $x$ & & & 3 & 27,2 \\
\hline & & Acomodação & & $x$ & & & $x$ & & $x$ & $x$ & & $x$ & $x$ & 6 & 54,5 \\
\hline
\end{tabular}

$1 \mathrm{~T}=$ total de observações; ${ }^{2} \mathrm{FT}=$ frequência total.

Fonte: resultados da pesquisa. 
A partir da análise da subcategoria Família, 45,5\% dos entrevistados afirmam que as mulheres tiveram maior conscientização dos direitos da família, 18,1\% tornaram-se menos submissas aos maridos e $27,2 \%$ relatam que houve diminuição da violência doméstica após a implementação do PBF.

Além desta maior conscientização dos direitos, 27,2\% dos entrevistados relatam que as mulheres procuram o Cras com o intuito de solicitar assistência jurídica, enquanto 36,3\% afirmam que houve mais casos de separação.

Isto expressa uma mudança na dominação tradicional dos homens-maridos, conforme verificou Costa (2000), pois garante mais autonomia às mulheres no que se refere ao controle de seus corpos, à sexualidade, ao direito de ir e vir, bem como ao sentimento de repulsa à violência física, pois $27,2 \%$ dos entrevistados afirmam que houve redução nos casos de violência doméstica.

Nas palavras de E3: "Alguns nos procuram com demanda à assistência jurídica, para poder se separar, ou pra poder denunciar violência doméstica" (E3).

Estes fatos também sinalizam para o empoderamento comunitário, que diz respeito à conquista e defesa de direitos (Mageste et al., 2008) e ao processo de expressão de necessidades, preocupações e tomada de decisões (OMS, 1998).

Parker (1991) considera que a renda básica proporciona um meio de independência financeira, não tira o direito de trabalhar fora de casa, mas pode aumentar a liberdade para as mulheres, que escolhem ficar em casa cuidando dos filhos.

Neste cenário, E9 reforça a mudança de comportamento das mulheres, ressaltando a insubmissão aos maridos e, principalmente, a independência das mulheres: "Hoje as mulheres são mais independentes. Procuram tirar dúvidas. Elas não são submissas aos maridos. Principalmente as que a gente atende. São bem atualizadas, sabem mais, correm mais atrás, não tudo, mas houve uma mudança bem grande em relação há alguns anos atrás" (E9).

Schiavo e Moreira (2005) afirmam que o empoderamento implica essencialmente a obtenção de informações adequadas, em um processo de reflexão e tomada de decisão, seguido de uma clara formulação de mudanças desejadas e da condição a ser construída.

Segundo Suplicy (2002), a mulher tem o direito não apenas à sua emancipação referente a seus direitos legais, econômicos ou políticos, mas também à sua libertação pessoal, fator este que o PBF pode proporcionar, segundo a percepção dos agentes contemplados na presente pesquisa.

Quanto à subcategoria Trabalho, embora as mulheres trabalhem muitas horas em casa todos os dias, esse trabalho não tem remuneração, sendo com frequência desconsiderado no cômputo contribuições para a prosperidade conjunta da família, pois a contribuição da mulher para a família é mais visível quando ela trabalha fora de casa e recebe salário (Sen, 2001).

Em relação ao trabalho, Schwarzman (2009) afirma que as beneficiárias do PBF têm uma participação da ordem de $2 \%$ a $3 \%$ no mercado de trabalho ligeiramente menor do que as não beneficiadas.

Este aspecto pode ser explicado de acordo com Parker (1991), segundo o qual a mulher, diferentemente do homem, precisa adaptar seu trabalho remunerado às suas responsa- 
bilidades familiares. Todavia, na década de 2010, em algumas camadas sociais, há indícios para modificação dos papéis sociais de homens e mulheres na família, com maior divisão de responsabilidades.

Neste tema, 45,4\% dos entrevistados afirmam que as mulheres não trabalham por medo de perder o benefício do PBF, enquanto 54,5\% afirmam que elas estão acomodadas com o PBF, provavelmente devido a uma resistência à formalização trabalhista, que poderia implicar seu cancelamento.

Entretanto, 36,3\% dos entrevistados afirmam que as mulheres realizam "bicos", enquanto $18,1 \%$ afirmam que elas participam de oficinas de geração de trabalho e renda e $27,2 \%$ afirmam que as mulheres realizam trabalhos sazonais, principalmente ligados à agricultura regional dos municípios.

Contudo, embora grande parte das mulheres não trabalhe fora de casa, apresentando resistência à formalização empregatícia, muitas trabalham esporadicamente para complementar a renda e se interessam em participar das palestras socioeducativas e de cursos, informações estas que, na perspectiva de Gohn (2004), apontam para o empoderamento individual e relacional das mulheres.

Nesta conjuntura, o processo de tomada de consciência e empoderamento é alcançado, porém não é homogêneo, pois, ao mesmo tempo que há um aumento de informação, qualificação e capacitação, há resistência em relação ao trabalho fora de casa, que poderia proporcionar uma renda maior e um empoderamento mais sólido às mulheres.

Portanto, surgem percepções de características empoderadoras, pois, na acepção de Bronzo (2008), as mulheres beneficiárias desenvolvem estratégias para superação da pobreza, buscando desenvolver competências, autonomia e capacidade de autodesenvolvimento, mesmo recebendo o benefício PBF.

\section{Considerações finais}

Resgatando algumas discussões mais importantes, constata-se que o PBF reflete-se na autonomia, autoestima e empoderamento individual das mulheres beneficiárias, ressaltando-se o status que a posse do cartão do PBF propõe para as mulheres, pois a maioria delas nunca possuiu conta ou frequentou agências bancárias, sendo este um fator que valoriza e pode legitimar as mulheres como cidadãs.

Em uma análise conjunta, a melhoria nas condições de vida, a inclusão social, a educação e a qualificação sugerem reflexos de empoderamento individual e relacional das mulheres.

Contudo, enfatiza-se a necessidade de maior informação e orientação a respeito do PBF e das condicionalidades, pois, apesar de a aplicação dos recursos do PBF ser realizada, na percepção dos agentes, de maneira adequada para a maioria das mulheres assistidas, ficou claro que a melhor compreensão, por parte das mulheres, sobre a importância do PBF tornaria mais fácil o cumprimento do que lhes é demandado. 
Confirmaram-se os efeitos positivos, que já eram supostos, quanto ao convívio no Cras, tanto para as famílias quanto para as mulheres, pois este proporciona apoio e converge em maior conscientização sobre os direitos. Os temas mais evidenciados foram a procura por assistência jurídica e o aumento do número de separações, o que pode indicar o rompimento das relações patriarcais e da dominação tradicional masculina, garantindo-lhes a autonomia no que se refere ao controle de seus corpos e à tomada de decisões.

A convivência e a participação nos Cras também contribuem para a compreensão sobre esta área do sistema público, além de melhoria do bem-estar, por intermédio de orientações e atendimento psicológico, o que sugere indicativos para o empoderamento comunitário, pois as mulheres começam a ter mais acesso às informações.

O fato de as mulheres beneficiárias não trabalharem regularmente fora de casa, principalmente devido ao receio de perder o Bolsa Família, induz a reflexões sobre as oportunidades e as condições de emprego que lhes são ofertadas. Muitas vezes, essas mulheres não dispõem de creches para deixar os filhos enquanto trabalham e nem ao menos possuem condições de pagar alguém para cuidar dos filhos, e o recebimento de um salário formal resultaria, muitas vezes, em um rendimento menor ou igual, podendo ser mais confortável receber o benefício e cuidar quase que exclusivamente da família, realizando trabalhos eventuais para complementar os ganhos.

A despeito de que seja um processo lento e embrionário, pode-se dizer que o ciclo do empoderamento das mulheres beneficiárias do PBF consegue ser alcançado, porque atinge as três dimensões (individual, familiar e comunitária).

Portanto, tais resultados demonstram a importância do Cras na execução do PBF e no processo de empoderamento das mulheres, além de suscitar outros questionamentos sobre quais seriam as consequências do empoderamento nas dimensões da pobreza e mobilidade social.

Seria interessante a replicação deste estudo em outras unidades do Cras, ou envolvendo outros grupos de sujeitos de pesquisa, como maridos das beneficiárias, professores dos filhos e mulheres não assistidas pelo PBF, ou ainda com o mesmo público-alvo, mas com o suporte de outras teorias como, por exemplo, a teoria do capital social, a teoria das representações sociais ou a teoria feminista.

\section{Referências}

AGENDE. Núcleo de Estudos e Pesquisa sobre a Mulher. Universidade de Brasília, 2006.

ANANIAS, P.; COELHO, M.F.R. Políticas sociais ajudam na inclusão econômica. Dez. 2009. In: <www. fomezero.gov.br/artigo/politicas-sociais-ajudam-na-inclusao-economica-patrus-ananias-e-mariafernanda-ramos-coelho $>$ Acesso em: 1ํ jul. 2010.

BARDIN, L. Análise de conteúdo. Lisboa: Edições, 2009. 
BOLSA FAMÍLIA INFORMA - NÚMERO 38. Governo Federal regulamenta apoio financeiro aos municípios para gestão do Bolsa Família. Disponível em: <www.mds.gov.br/bolsafamilia/menu_superior/informe-pbf/informe-pbf gestores/paginas/informebolsafamilia_edicao38.htm>. Acesso em: 3 jan. 2008.

BRONZO, C. Distintas visões sobre a pobreza: elementos de um debate implícito. Disponível em: <http://portalpbh.pbh.gov.br/pbh/ecp/files.do?evento=download\&urlArqPlc=pensarbh20_politicas_sociais_.pdf>. Acesso em: 15 out. 2009.

BRONZO, C. Vulnerabilidade, Empoderamento e Proteção Social. Reflexões a partir de experiências latino-americanas. In: ENANPAD, XXXII, 2008.

COADY, D.P.; PARKER, S. A cost-effectiveness analysis of demand- and supply-side education interventions: the case of Progresain Mexico. Centro de Investigación y Docencia Económicas (Cide) — Divisão de Economia. Review of Development Economics, v. 8, n. 3, p. 440-451, ago. 2004.

COSTA, A.A. Gênero, poder e empoderamento das mulheres. Núcleo de Estudos Interdisciplinares sobre a Mulher (Neim/Ufba), 2000.

DRAIBE, S.M. Uma nova institucionalidade das políticas sociais? Reflexões a propósito da experiência latino-americana recente de reformas dos programas sociais. Revista São Paulo em Perspectiva: Revista da Fundação Sead, São Paulo, v. 11, n. 4, p. 3-21, 1997.

FIALHO, P.J.F. O programa Bolsa Família em São Luís (MA) e Belém (PA): um estudo sobre a relação entre gestão local e os efeitos do programa na condição de vida das mulheres. Dissertação (mestrado) — Programa de Pós-Graduação em Política Social, Universidade de Brasília, Brasília, 2007.

FÓRUM ECONÔMICO MUNDIAL. Empoderamento de mulheres: avaliação das disparidades globais de gênero. Genebra, 2005.

FRANCO, M.L.P.B. Análise de conteúdo. 2. ed. Brasília: Líber Livro, 2005.

GIL, A.C. Como elaborar projetos de pesquisa. 6. ed. São Paulo: Atlas, 2006.

GITTER, S.R.; BARHAM, B.L. Women's power, conditional cash transfers, and schooling in Nicaragua. World Bank Econ. Rev., v. 1, May 22, 2008.

GOHN, M.G. Empoderamento e participação da comunidade em políticas sociais. Saúde e Sociedade, v. 13, n. 2, p. 20-31, ago. 2004.

IBGE. Censo demográfico 2009. Disponível em: <www.ibge.gov.br>. Acesso em: maio 2010.

KLEIN, C. Mulher e família no Programa Bolsa-Escola: maternidades veiculadas e instituídas pelos anúncios televisivos. Cadernos Pagu, Campinas, n. 29, dez. 2007.

LEOPARDI, M.T.; RODRIGUES, M.S.P. O método de análise de conteúdo. Fortaleza: Fundação Cearense de Pesquisa e Cultura, 1999.

MAGESTE, G.S.; MELO, M.C.O.L.; CKAGNAZAROFF, I.B. Empoderamento de Mulheres: uma proposta de análise para organizações. In: ENCONTRO DE ESTUDOS ORGANIZACIONAIS DA ASSOCIAÇÃO NACIONAL DE PÓS-GRADUAÇÃO EM ADMINISTRAÇÃO, V, Belo Horizonte, 2008. 
MEDEIROS, M.; COSTA, J. What do we mean by feminization of poverty? Centro Internacional da Pobreza, n. 58, Out. 2008. Disponível em: <www.undp-povertycentre.org/pub/IPCOnePager58. pdf>. Acesso em: 25 out. 2009.

MINISTÉRIO DO DESENVOLVIMENTO SOCIAL E COMBATE À FOME. MDS em números. Disponível em: <http://aplicacoes.mds.gov.br/sagi/ascom/index.php?cut=aHR0cDovL2FwbGljYWNvZXMu bWRzLmdvdi5ici9zYWdpL2FzY29tL2dlcmFyL2luZGV4LnBocA $==\& d e f=v>$. Acesso em: 23 maio 2010 .

MINISTÉRIO DO DESENVOLVIMENTO SOCIAL E COMBATE À FOME. Norma operacional básica de recursos humanos do Suas. Brasília, 2006a.

MINISTÉRIO DO DESENVOLVIMENTO SOCIAL E COMBATE À FOME. Orientações Técnicas do Centro de Referência de Assistência Social — Cras. Brasília, 2009.

MINISTÉRIO DO DESENVOLVIMENTO SOCIAL E COMBATE À FOME. Política Nacional de Assistência Social (PNAS). Brasília: MDS \SNAS, 2004.

MINISTÉRIO DO DESENVOLVIMENTO SOCIAL E COMBATE À FOME. Suas: Sistema Único de Assistência Social. Brasília, 2006b.

MONNERAT, G.L. et al. Do direito incondicional à condicionalidade do direito: as contrapartidas do Programa Bolsa Família. Ciência \& Saúde Coletiva, v. 12, n. 6, p. 1453-1462, 2008.

MONTEIRO, D.A.A. Alocação de recursos e eficiência na gestão do Programa Bolsa Família. Dissertação (mestrado em administração) — Universidade Federal de Viçosa, Viçosa, 2008.

MOORE, C. Nicaragua's Red de Protección Social: an exemplary but short-lived conditional cash transfer programme. International Policy Centre for Inclusive Growth, UNDP Country Study number 1, 2009. Disponível em: <www.ipcundp.org/pub/IPCCountryStudy17.pdf>. Acesso em: 10 jun. 2010.

ORGANIZAÇÃO MUNDIAL DE SAÚDE. Glossary of health promotion terms. Geneva: World Health Organization/Division of Health Promotion, Educations and Communications/Health Education and Health Promotion Unit, 1998.

PARKER, H. Basic income and the labour market. London: Basic Income Research Group, 1991.

PNUD. Programa das Nações Unidas para o Desenvolvimento. Relatório de desenvolvimento humano 2007-2008. Disponível em: <www.pnud.org.br/rdh/>. Acesso em: 20 jun. 2010.

RAWLINGS, L.B.; RUBIO, G.M. Evaluating the impact of Conditional Cash Transfer Programs. The World Bank Research Observer, 2005. Disponível em: <www.undp-povertycentre.org/publications/ mds/33P.pdf>. Acesso em: 21 out. 2009.

ROMANO, J.O. Empoderamento e direitos no combate à pobreza. Rio de Janeiro: ActionAid, 2002.

RUBALCAVA, L. et al. Investments, time preferences, and public transfers paid to women. Economic Development and Cultural Change, v. 57, n. 3, p. 507-538, 2009. 
RUSSO, O. O Cras e a nova assistência social. Disponível em: <www.fomezero.gov.br/artigo/o-crase-a-nova-assistencia-social-osvaldo-russo >. Acesso em: 1o jul. 2010.

SCHIAVO, Márcio R.; MOREIRA, Eliesio N. Glossário social. Rio de Janeiro: Comunicarte, 2005.

SCHWARZMAN, S. Bolsa Família: mitos e realidades. Instituto de Estudos do Trabalho e Sociedade, Interesse Nacional, ano 2, n. 7, p. 20-28, dez. 2009.

SEN, A.K. Desenvolvimento como liberdade. São Paulo: Companhia das Letras, 2001.

SEN, G. Empowerment as an approach to poverty. Background paper for human development report 1997.Working Paper Series, n. 97-07, 1997.

SILVA, M.O.S.; YAZBEK, M.C.; GIOVANNI, G. A política social brasileira no século XXI: a prevalência dos programas de transferência de renda. 3. ed. São Paulo: Cortez, 2007.

SUARÉZ, M. et al. O Programa Bolsa Família e o enfrentamento das desigualdades de gênero: o desafio de promover o reordenamento do espaço doméstico e o acesso das mulheres ao espaço público. Brasília: Agende, 2006.

SUPLICY, E.M. Renda de cidadania: a saída é pela porta. São Paulo: Cortez/Fundação Perseu Abramo, 2002.

UPHOFF, N.T. Grass roots organizations and NGOs in rural development: opportunities with dresiminishing states and expanding markets. World Development, v. 21, n. 4, p. 607-622, 1993.

VILLATORO, P. Conditional cash transfer programmes: experiences from Latin America. Cepal Review, n. 86, p. 83-96, 2005.

YIN, R.K. Estudo de caso: planejamento e método. 2. ed. São Paulo: Bookman, 2001.

Nathalia Carvalho Moreira é mestre em administração pela Universidade Federal de Viçosa (UFV). Email: nathaliatp@yahoo.com.br.

Marco Aurélio Marques Ferreira é professor do Programa de Pós-Graduação em Administração da UFV. E-mail: marcoaurelio@ufv.br.

Afonso Augusto Teixeira de Freitas Carvalho Lima é professor do Programa de Pós-Graduação em Administração da UFV. E-mail: afonsoli@ufv.br.

Ivan Beck Ckagnazaroff é professor adjunto da Universidade Federal de Minas Gerais. E-mail: ivanbeck@ face.ufmg.br. 
